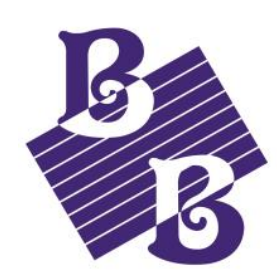

BioBacta
Journal of Bioscience and Applied Research www.jbaar.org

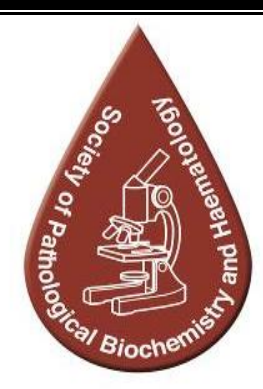

\title{
Factors attributing to obesity among working adults in Egypt
}

Mai Sabry Saleh ${ }^{1}$, Eman Essam Shaban ${ }^{1}$, and Nagat Amer ${ }^{1}$

Environmental and Occupational Medicine Department, Environmental Research Division, National Research Centre ${ }^{1}$ 33 Elbehouth street, Dokki, Giza, Egypt

(nouranomer@gmail.com)

DOI: 10.21608/jbaar.2018.152674

\section{Abstract}

Obesity is a growing epidemic problem. Many environmental factors at the workplace like occupational stress and job satisfaction attribute to obesity either as a cause or consequence. Other seriously contributing factors are of socio-demographic and health-related nature. The present study aimed to investigate the association between some environmental and health-related variables and obesity in terms of Body Mass Index (BMI) among working adults in Egypt. A cross-sectional study was carried on a convenient sample of 86 males and females working in the public sector. All participants completed the Perceived Stress Scale, Falsification of Type quiz, Andrews and Withey test for Job Satisfaction and a sheet for socio-demographic, health and workrelated data. Blood samples were obtained and assessments of cortisol, C-reactive protein, dehydroepiandrosterone sulfate and total thyroxin were done using the ELISA technique. Total cholesterol and triglycerides were assessed colourimetrical. BMI and $\mathrm{W} / \mathrm{H}$ were calculated. Pearson correlation test was performed for statistical analysis. Advanced age, female gender, presence of chronic diseases, presence of mental health problems, increased level of CRP and decreased level of DHEA-S were factors showing a significant correlation with increased BMI. In conclusion, an extensive study of predictors of obesity is a crucial need among working adults in Egypt.

Keywords: BMI, job satisfaction, falsification of type, mental health problems, obesity, perceived stress, stress biomarkers

\section{Introduction}

Obesity is a major health challenge worldwide (Shamseddeen et al., 2011). It turned out to be an epidemic and nowadays is regarded as a critical public health problem ( $\mathrm{Ng}$ et al., 2014). Obesity increases the risk of cardiovascular diseases, cancer, diabetes and early deaths (Flegal et al, 2013). Besides, obesity represents one cause of elevated medical costs and aggravate the financial burden on employers (Trogdon et al., 2012).

Unfortunately, many factors, at work, could drive employees to an unhealthy lifestyle that results in weight gain. A prominent factor of which is work stress that promotes unfavourable diet practices and low physical activity (Kirk and Rhodes, 2011). Stress increases reward signals from the brain in response to fatty meals (Zellner et al., 2006) and decreases it after fruit intake (Liu et al., 2007). Additionally, stress disrupts physiological regulation by increasing cortisol level that is lipogenic (Lee and Fried, 2014) and leads to an accumulation of abdominal fat (Rosmond, 2003). Work-stress is also reported to be closely related to psychological problems like anxiety, depression and emotional disturbances (Morse et al., 2011) that play a significant role as a major risk factor for obesity.

Increased perceived stress (PS) compared to normal stress, in particular, showed great association with 
more consumption of snack foods over fruit (El Ansari et al., 2014), excessive binge eating (Pendleton et al, 2001) and increased problem of disinhibition (Haynes et al., 2003). PS is used as a measure of work-stress psychometrically. Job satisfaction and falsification of type are also used to determine work stress in terms of how much employees love their work and to what extent the job is matched with their natural lead and personal talents, respectively.

For the assessment of stress, some biomarkers are highly recommended in addition to psychometric determination (McCarty et al., 2009). The most suggested assessments are for cortisol, C-reactive protein (CRP), triglycerides, cholesterol (Torres and Nowson, 2007), dehydroepiandrosterone sulphate (DHEA-S) and thyroid hormones.

Gender has been reported as another risk factor for obesity in the workplace. Females with low socioeconomic status were found to be the most suffering from severe obesity (Wang and Beydoun, 2007). Females also showed an increase in BMI with time according to Magee et al. (2010) while Marchand et al. (2015) found it to be significant among men not women. In the workplace, high demands were associated with increased BMI in both men and women (Kivimaki et al., 2006). Similarly, loss of control and authority over decision making reported an association with obesity in both genders (Berset et al., 2011). Significant findings were found about the role of job strain that is defined as low control accompanied by psychological demands among the female gender (Eek and Ostergren, 2009). On the other hand, isostrain that describes low control, high psychological demands and low social support at work significantly contributed to obesity among the males only (Brunner et al., 2007).

Other than stress and gender, age is a non-workrelated factor showing a relationship with BMI. Age showed controversial results, some favoured direct association (Sund et al., 2010) while others emphasized the inverse relationship with BMI (Hannerz et all., 2004). Educational level is another non-work-related risk factor that showed an inverse relation to BMI and contributed to obesity (Dugravot et al., 2010). Marital status has also been studied as a non-work risk factor of obesity among working adults. As reported, being single didn't contribute to increased BMI over time in both males and females (Iversen et al., 2012). Married women showed a direct association between work-family conflicts and increased BMI (Lallukka et al., 2005).

Much is still needed to be investigated concerning factors attributing to obesity among working adults in different communities and environments. Work and non-work-related variables overlap in their causaleffect relationship with obesity and even interact with each other. Controversial results are also obtained about the significance of the different risk factors by changing sample characteristics, environmental contexts and study nature and design. The present work is an attempt to explore the relationship between some of the aforementioned attributing factors to obesity and BMI among a sample of adults working in the governmental sector in Egypt.

\section{Materials and Methods}

A cross-sectional descriptive study was performed on a convenient sample of 86 participants working as employees or workers at different governmental sectors in Egypt and from both genders. All participants were interviewed for completing the ten items Perceived Stress Scale (PSS-10) (Cohen et al., 1983), Falsification of Type quiz (retrieved from http://personalitycafe.com/cognitive-functions/40393falsifying-type-quiz.html) for assessment of work stress, Job Satisfaction Scale (JSS) (Andrews and Withey, 1976) and a sheet for some sociodemographic, health state and work-related factors. PSS scores ranged between 0 and 40 after a four-point Likert scale. Up to 13 represented low PS, $>13$ and $<27$ indicated mild PS and $>26$ denoted sever PS. A three-point Likert scale comprised response choices in the Falsification of Type quiz with scores ranging between 0 and 32. Increases in the score showed more degree of falsification at work and hence more experience of work-stress. As for the JSS, it is made up of five sentences with 7 Likert points where the lower values corresponded to satisfaction with a job while higher values corresponded to job dissatisfaction. A value of 20 denoted neither satisfied nor dissatisfied.

Serum samples were collected for biochemical assessments. Cortisol, DHEA-S, CRP and total thyroxine (tT4) were assessed using the enzymelinked immunosorbent assay (ELISA) technique. Kits in use were; Immunospect kit (CA) for cortisol and tT4 and an ELISA kit manufactured by DRG diagnostics, Germany for DHEA-S and CRP. A biodiagnostic kit (Egypt) was used to estimate serum levels of total cholesterol (TC) and triglycerides (TG) after colourimetric methods illustrated by Allain et al. (1974) and Fassati and Principe (1982), respectively. Normal ranges of the assessed markers are as follows; $5-23 \mu \mathrm{g} / \mathrm{dl}$ for cortisol, $0.1 \mu \mathrm{g} / \mathrm{ml}-10 \mu \mathrm{g} / \mathrm{ml}$ for DHEA-S, 0.068-8.2 mg/l for CRP, $5-13 \mu \mathrm{g} / \mathrm{dl}$ for tT4, 
$150-225 \mathrm{mg} / \mathrm{dl}$ for TC and $40-140 \mathrm{mg} / \mathrm{dl}$ for women and $60-165 \mathrm{mg} / \mathrm{dl}$ for men for TG,

Waist circumference and hip circumference were used to calculate waist to hip ratio (WHR) according to the procedure detailed by Lohman et al. (1988) and BMI was calculated in kilograms divided by height in meter square (Seplaki et al., 2005). BMI exceeding 30 indicated obesity (Crimmins et al., 2003) and WHR normal value were $>0.90$ for men and $>0.85$ for women (World Health Organization, 1999). Consent forms were signed by all participants and ethical approval was received from the ethical committee at the National Research Centre for performing the study procedures.

Statistical analysis was done using the Statistical Package for Social Sciences (SPSS 23) (SPSS Inc., Chicago, IL, USA). Descriptive statistics and Pearson correlation were performed. A p-value of less than 0.05 was considered significant.

\section{Results}

Females represented $70 \%$ of the study sample. Most participants were married, living in the urban areas, with low income and education level, living far from their workplace and work for more than five hours daily (table 1).

Table1. Frequency distribution of participants' characteristics

\begin{tabular}{|lll|}
\hline Study variables (N) & & $\begin{array}{l}\text { Frequency } \\
(\%)\end{array}$ \\
\hline Gender (86) & Male & $26(30)$ \\
& Female & $60(70)$ \\
Marital status (83) & Single & $26(31)$ \\
& Married & $57(69)$ \\
Residence (81) & Urban & $74(91)$ \\
& Rural & $7(9)$ \\
\hline Monthly income (79) & $<1200$ LE & $51(65)$ \\
& $<3000 \mathrm{LE}$ & $21(27)$ \\
& $<5000 \mathrm{LE}$ & $7(8)$ \\
Education level (77) & Low & $17(22)$ \\
& Medium & $42(55)$ \\
& High & $18(23)$ \\
\hline Chronic diseases (86) & No & $57(66)$ \\
& Yes & $29(34)$ \\
Mental health problems (85) & No & $79(93)$ \\
& Yes & $6(7)$ \\
\hline Distance from work (82) & Near & $26(30)$ \\
& Far & $56(65)$ \\
Other jobs (84) & No & $70(83)$ \\
& Yes & $14(17)$ \\
Working years (81) & $<10$ & $37(46)$ \\
& $\geq 10$ & $44(54)$ \\
Working hours (31) & $3-5$ hrs & $8(26)$ \\
& $>5$ hrs & $23(74)$ \\
\hline
\end{tabular}

The mean age of participants was 40.3 years ranging between 20 and 59. As shown in table2, they had BMI and WHR mean values exceeding the obesity level. No experience of job dissatisfaction, perceived stress or work stress since all means appeared within normal ranges. Similarly, for all biomarkers; mean values didn't break normal range levels.

As shown in table 3, BMI was significantly associated with higher age and female gender. Rural residence and married subjects had higher BMI yet non-significant. Neither of the socioeconomic variables under study showed significance with BMI but it could be noticed that lower-income and higher education pertain more to obesity. Chronic diseases showed to be significantly abundant among those with higher BMI as well as mental health problems. Among the work-related variables, none of the parameters showed a correlation with BMI at the time where higher CRP and lower DHEA-S biomarkers showed a significant association.

\section{Discussion}

According to our results, factors that showed a significant direct association with increased BMI were; advanced age, female gender, presence of chronic diseases, presence of mental health problems, increased level of CRP biomarker and decreased level of DHEA-S biomarker.

In contradiction with our hypothesis, work stress didn't show any significance in association to obesity neither when assessed psychometrically in terms of perceived stress, job satisfaction and falsification of type nor when measured biochemically using cortisol and other related biomarkers like TG, TC and thyroxin. An exception was detected for CRP and DHEA-S that could be related to other factors among the study sample than stress. Similar findings were reported by some research studies (Faghri et al., 2015; Pollard et al., et al.1995; Griffin et a., 1993) that emphasized disconnection between dietary behaviours inviting obesity and stress. The level of cortisol among the study sample, being at the normal level, also favoured exclusion of the assumption that increased BMI was due to the lipogenic effect of increased secretion of cortisol in response to the prevalence of stress. 
According to the literature, increased CRP could be due to the released fatty acids from visceral and/or abdominal adipose tissue (Misra and Vikram, 2003) that has no direct relation to stress. CRP has also been reported to correlate positively with BMI and WHR among African women (Lear et al., 2003) and especially in hypertensive cases (Schutte et al., 2008). Similarly, the negative correlation between DHEA-S levels and BMI could be explained apart from assuming the presence of stress. In agreement with our findings, DHEA-S is lower in the serum of obese Saudi women compared to matched normal cases and showed a significant negative correlation with BMI. Other studies indicated that low levels of DHEA-S were a causal effect for obesity (Manson et al., 1995). DHEA-S was also reported to contribute to the pathogenesis of mental health problems like depression (Baumgartner et al., 1995) that is significantly associated with BMI in our study sample. However, some studies showed different results concerning the relationship between obesity and sulfate ester of DHEA summed up by (Villareal et al., 2005) who emphasized inconsistent findings.

As declared by cross-sectional studies, BMI increase by age -that is the cases in our study- and reach peak values between 50 and 60 years (Flegal et al., 2002).

Table 2. Descriptive data of age, biomarkers levels and measured scales.

\begin{tabular}{|c|c|c|c|c|}
\hline & $N$ & Mean \pm SD & Minimum & Maximum \\
\hline Age & 86 & $40.3 \pm 10.6$ & 20 & 59 \\
\hline BMI & 72 & $31.4 \pm 6.2$ & 18.1 & 47.5 \\
\hline Job Satisfaction & 81 & $15.6 \pm 4.5$ & 8 & 25 \\
\hline Perceived Stress & 83 & $21.5 \pm 6.3$ & 0 & 36 \\
\hline Work Stress & 66 & $12.1 \pm 6.4$ & 1 & 27 \\
\hline HDL & 75 & $63.1 \pm 31.0$ & 22 & 201 \\
\hline TC & 78 & $193.9 \pm 73.0$ & 40 & 460 \\
\hline TG & 78 & $129.7 \pm 68.6$ & 48 & 560 \\
\hline CRP & 72 & $4.4 \pm 3.0$ & 0.5 & 9.7 \\
\hline Cortisol & 80 & $11.2 \pm 3.9$ & 3.8 & 19.7 \\
\hline tT4 & 75 & $9.3 \pm 2.4$ & 4.7 & 14.8 \\
\hline DHEA-S & 78 & $0.8 \pm 0.6$ & 0.03 & 3.5 \\
\hline WHR & 74 & $0.9 \pm 0.2$ & 0.7 & 1.9 \\
\hline
\end{tabular}

Body composition changes by the effect of age where fat mass increases on the expenses of fat-free mass represented by skeletal muscles (Muller et al., 1996) and relocates to be concentrated at the abdominal region (Beaufrere et al., 2000).

Table 3. Bivariate correlations between BMI and study variables.

\begin{tabular}{|llll|}
\hline & Study variables & $\boldsymbol{R}$ & $\boldsymbol{P}$ \\
\hline $\begin{array}{l}\text { Socio- } \\
\text { demographics }\end{array}$ & Age & $\mathbf{0 . 4 7 8} *$ & $\mathbf{0 . 0 0 0}$ \\
& Gender & $\mathbf{0 . 2 8 7 ^ { * }}$ & $\mathbf{0 . 0 1 5}$ \\
& Marital status & $\mathbf{0 . 2 3 1}$ & $\mathbf{0 . 0 5 6}$ \\
& Residence & $\mathbf{- 0 . 1 0 1}$ & $\mathbf{0 . 4 1 4}$ \\
\hline Socioeconomic & Monthly income & $\mathbf{- 0 . 0 1 7}$ & $\mathbf{0 . 8 9 5}$ \\
status & Education level & $\mathbf{0 . 0 6 6}$ & $\mathbf{0 . 6 0 1}$ \\
\hline Health-related & Chronic diseases & $\mathbf{0 . 3 2 4} * *$ & $\mathbf{0 . 0 0 5}$ \\
& Mental health & $\mathbf{0 . 2 6 0} *$ & $\mathbf{0 . 0 2 7}$ \\
& problems & & \\
& Perceived stress & $\mathbf{0 . 1 8 1}$ & $\mathbf{0 . 1 3 6}$ \\
& Waist to hip ratio & $\mathbf{0 . 1 3 0}$ & $\mathbf{0 . 2 7 8}$ \\
\hline Work-related & Distance from & $-\mathbf{0 . 1 6 3}$ & $\mathbf{0 . 1 8 3}$ \\
& work & & \\
& Other jobs & $-\mathbf{0 . 1 2 8}$ & $\mathbf{0 . 2 9 1}$ \\
& Working years & $\mathbf{0 . 2 1 7}$ & $\mathbf{0 . 0 7 4}$ \\
& Working hours & $-\mathbf{0 . 1 4 8}$ & $\mathbf{0 . 4 3 6}$ \\
& Job satisfaction & $\mathbf{- 0 . 7 1}$ & $\mathbf{0 . 5 6 5}$ \\
& Work stress & $\mathbf{0 . 0 4 5}$ & $\mathbf{0 . 7 4 5}$ \\
\hline TC & $\mathbf{- 0 . 0 3 9}$ & $\mathbf{0 . 7 4 9}$ \\
& TG & $\mathbf{0 . 1 7 3}$ & $\mathbf{0 . 1 5 1}$ \\
& HDL & $-\mathbf{0 . 0 2 2}$ & $\mathbf{0 . 8 5 8}$ \\
& Cortisol & $\mathbf{- 0 . 1 8 1}$ & $\mathbf{0 . 1 2 9}$ \\
& CRP & $\mathbf{0 . 3 8 0} *$ & $\mathbf{0 . 0 0 1}$ \\
& DHEA-s & $\mathbf{- 0 . 2 5 4} *$ & $\mathbf{0 . 0 3 2}$ \\
& tT4 & $\mathbf{0 . 1 0 2}$ & $\mathbf{0 . 3 9 4}$ \\
\hline
\end{tabular}

* Correlation is significant at the 0.05 level, ** Correlation is highly significant at the 0.01 level.

Females in our study suffered more than males from obesity following many similar kinds of research (Lallukka et al., 2008). At the same time, neither being single nor married seemed to affect obesity in agreement with findings of Block et al. (2009) and Iversen et al. (2012), respectively. On the other hand, mental health problems showed a significant association with BMI. Previous research suggested the presence of causal effects between environmental conditions, mental health and obesity, yet little is known about details or mechanisms (Barry and Petry, 2008; Andersen et al., 2004). Mental health disturbances affect appetite either positively or negatively with an obvious risk of weight gain (Kivimäki et al., 2006). Besides, psychotropic drugs are evident to increase the appetite with an inventible consequence of obesity (Smits et al, 2010). Chronic diseases also showed a direct correlation with increased BMI in agreement to many research findings that emphasized obesity as a risk factor for many of them (Flegal et al., 2013, Egger and Dixon, 2014). As reported, obesity is associated with lowgrade systemic inflammation and insulin resistance (Egger and Dixon, 2009) and prolonged dysregulation of an immune response (Pal et al., 2016) that offered 
some causal explanations for chronic diseases in consequence of obesity.

In conclusion, it is highly recommended to investigate both work and non-work environmental factors affecting obesity since both have been reported to seriously contribute to obesity. Biochemical assessments also can highlight different pathways and mechanisms of pathogenesis of gaining weight. Further analysis of present data is recommended that include linear regression analysis of findings to detect the exact predictors of obesity among the significantly correlated variables. Repeating the study on a larger sample would help to obtain results that could be generalized. More research investigating the relationship between obesity and work-stress models, management standards and a healthy workplace is crucial for a better understanding of risk factors of obesity at the workplace.

\section{References}

Allain, C.C., Poon, L.S., Chan, C.S., Richmond, W., Fu, P.C. (1974). Enzymatic determination of total serum cholesterol. Clin Chem., 20(4):470-475. PMid:4818200

Andersen, I., Burr, H., Kristensen, T.S., et al. (2004). Do factors in the psychosocial work environment mediate the effect of socioeconomic position on the risk of myocardial infarction? Study from the Copenhagen Centre for Prospective Population Studies. Occup Environ Med., 61(11):886-892.

Andrews, F.M., Withey, S.B. (1976). Social indicators of well-being: American's perceptions of life quality. New York: Plenum Press. http://dx.doi.org/10.1007/978-1-4684-2253-5

Barry, D., Petry, N. (2008). Gender differences in associations between stressful life events and body mass index. Prev Med., 47:498-503.

Baumgartner, R.N., Stauber, P.M., McHugh, D., Koehler, K.M., Garry, P.J. (1995). Cross-sectional age differences in body composition in persons 60_years of age. J Gerontol A Biol Sci Med Sci., 50:M307-316.

Beaufrere, B., Morio, B. (2000). Fat and protein redistribution with aging: metabolic considerations. Eur J Clin Nutr., 54(suppl): S48 -53.

Berset, M., Semmer, N.K., Elfering, A., et al. (2011). Does stress at work make you gain weight? A twoyear longitudinal study. Scand J Work Environ Health, 37:45-53.

Block, J.P., He, Y., Zaslavsky, A.M., et al. (2009). Psychosocial stress and change in weight among US adults. Am J Epidemiol., 170:181-192.
Brunner, E.J., Chandola, T., Marmot, M.G. (2007). Prospective effect of job strain on general and central obesity in the Whitehall II study. Am J Epidemiol., 165:828-837.

Cohen, S. and Williamson, G. (1988). Perceived Stress in a Probability Sample of the United States. Spacapan, S. and Oskamp, S. (Eds.) The Social Psychology of Health. Newbury Park, CA: Sage.

Crimmins, E.M., Johnston, M., Hayward, M., Seeman, T. (2003). Age dysregulation. Exp Gerontol. 38(7):731-734.http://dx.doi.org/10.1016/S05315565(03)00099-8

Eek, F., Ostergren, P.O. (2009). Factors associated with BMI change over five years in a Swedish adult population. Results from the Scania public health cohort study. Scand J Public Health., 37:532-544.

Egger, G., Dixon, J. (2009). Obesity and chronic disease: always offender or often just accomplice? Br J Nutr., 102(8):1238-1242. DOI: 10.1017/S0007114509371676. Epub 2009 May 18.

Egger, G., Dixon, J. (2014). Beyond obesity and lifestyle: a review of 21st-century chronic disease determinants. Biomed Res Int., 731685. DOI: 10.1155/2014/731685. Epub 2014 Apr 7.

El, Ansari. W., Adetunji, H., Oskrochi, R. (2014). Food and mental health: relationship between food and perceived stress and depressive symptoms among university students in the United Kingdom. Cent Eur J Public Health, 22(2):90-97.

Faghri, P.D., Mignano, C., Cherniack, M. and HuedoMedina, T.B. (2015). Psychological Health and Overweight and Obesity Among High Stressed Work Environments. Obesity, 1.1: http://dx.doi. org/10.16966/2380-5528.101

Flegal, K.M., Carroll, M.D., Ogden, C.L., Johnson, C.L. (2002). Prevalence and trends in obesity among US adults, 1999-2000. JAMA, 288:1723-1727.

Flegal, K.M., et al. (2013). Association of All-Cause Mortality with Overweight and Obesity Using Standard Body Mass Index Categories. JAMA, 309:71-82.

Fossati, P., Prencipe, L. (1982). Serum triglycerides determined colorimetrically with an enzyme that produces hydrogen peroxide. Clin Chem., 28(10):2077-2280. PMid:6812986

Griffin, K.W., Friend, R., Eitel, P., Lobel, M. (1993). Effects of environmental demands, stress, and mood on health practices. J Behav Med., 16: 643- 661.

Hannerz, H., Albertsen, K., Nielsen, M.L., et al. (2004). Occupational factors and 5-year weight change among men in a Danish National Cohort. Health Psychol., 23:283-288.

Haynes, C., Lee, M.D., Yeomans, M.R. (2003). Interactive effects of stress, dietary restraint, and 
disinhibition on appetite. Eat Behav., 4(4):369-83. doi:10.1016/j.eatbeh.2003.07.005.

Iversen, L.B., Strandberg-Larsen, K., Prescott, E., et al. (2012). Psychosocial risk factors, weight changes and risk of obesity: the Copenhagen City Heart Study. Eur J Epidemiol., 27:119-30.

Kirk, M.A., Rhodes, R.E. (2011). Occupation correlates of adults' participation in leisure-time physical activity: a systematic review. Am J Prev Med., 40: 476-485.

Kivimäki, M., Head, J., Ferrie, J.E., Shipley, M.J., Brunner, E., Vahtera, J. et al. (2006). Work stress, weight gain and weight loss: evidence for bidirectional effects of job strain on body mass index in the Whitehall II study. Int J Obes., 30:982987.

Lallukka, T., Laaksonen, M., Martikainen, P., et al. (2005). Psychosocial working conditions and weight gain among employees. Int J Obes., 29:909-915.

Lallukka, T., Sarlio-Lahteenkorva, S., Kaila-Kangas, L., et al. (2008). Working conditions and weight gain: a 28-year follow-up study of industrial employees. Eur J Epidemiol., 23:303-310.

Lear, S.A., Chen, M.M., Birmingham, C.L., Frohlich, J.J. (2003). The relationship between simple anthropometric indices and C-reactive protein: ethnic and gender differences. Metabolism, 52(12): 1542-1546.

Lee, M-J., Fried, S.K. (2014). The glucocorticoid receptor, not the mineralocorticoid receptor, plays the dominant role in adipogenesis and adipokine production in human adipocytes. Int $\mathrm{J}$ Obes., 38:1228-1233. doi:10.1038/ijo.2014.6.

Liu, C., Xie, B., Chou, C-P., Koprowski, C., Zhou, D. Palmer, P., et al. (2007). Perceived stress, depression and food consumption frequency in the college students of China seven cities. Physiol Behav., 2:748-754.

Lohman, T.G., Roche, A.F., Martorell, R. (1988). Anthropometric Standardization. Champaign, IL: Human Kinetics Books. PMCid:PMC279682

Magee, C.A., Caputi, P., Stefanic, N., et al. (2010). Occupational factors associated with 4-year weight gain in Australian adults. J Occup Environ Med., 52:977-981.

Manson, J.E., Willett, W.C., Stampfer, M.J., et al. (1995). Body weight and mortality among women. N Engl J Med., 333:677- 685.

Marchand, A., Beauregard, N., Blanc, M-E. (2015). Work and non-work stressors, psychological distress and obesity: evidence from a 14-year study on Canadian workers. BMJ Open., 5:e006285. doi:10.1136/bmjopen-2014-006285
McCraty, R., Atkinson, M., Lipsenthal, L., Arguelles, L. (2009). New hope for correctional officers: an innovative program for reducing stress and health risks. Appl Psychophysiol Biofeedback., 34: 251272.

Misra, A., Vikram, N.K. (2003). Clinical and pathophysiological consequences of abdominal adiposity and abdominal adipose tissue depots. Nutrition., 19: 457-466.

Morse, T., Dussetschleger, J., Warren, N., Cherniack, M. (2011). Talking about health: correction employees' assessments of obstacles to healthy living. J Occup Environ Med., 53: 1037-1045.

Muller, D.C., Elahi, D., Tobin, J.D., Andres, R. (1996). The effect of age on insulin resistance and secretion: a review. Semin Nephrol., 16:289-298.

Ng, M., Fleming, T., Robinson, M., Thomson, B., Graetz, N., Margono, C. et al. (2013). Global, regional, and national prevalence of overweight and obesity in children and adults during 1980-2013: a systematic analysis for the Global Burden of Disease Study 2013. Lancet, 384: 766-781.

Pal, H.C., Pearlman, R.L., Afaq, F. (2016). Fisetin and Its Role in Chronic Diseases. Adv Exp Med Biol., 928:213244.

Pendleton, V.R., Willems, E., Swank, P., Poston, W.S., Goodrick, G.K., Reeves, R.S., et al. (2001). Negative stress and the outcome of treatment for binge eating. Eat Disord., 9(4):351-60. doi:10.1080/106402601753454912.

Pollard, T.M., Steptoe, A., Canaan, L., Davies, G.J., Wardle, J. (1995). Effects of academic examination stress on eating behavior and blood lipid levels. Int $\mathrm{J}$ Behav Med., 2: 299-320.

Rosmond, R. (2003). Stress induced disturbances of the HPA axis: a pathway to Type 2 diabetes? Med Sci Monit., 9(2): RA35-9. 3321.

Schutte, A.E., Huisman, H.W., van Rooyen. J,M., Schutte, R., Malan, L., Reimann, M., et al. (2008). Should obesity be blamed for the high prevalence rates of hypertension in black South African women? J Hum Hypertens., 22: 528-536.

Seplaki, C.L., Goldman, N., Glei, D., Weinstein, M.A. (2005). Comparative analysis of measurement approaches for physiological dysregulation in an older population. Exp Gerontol., 40(5):438-449. http://dx.doi.org/10.1016/j.exger.2005.03.002 PMid:15919596

Shamseddeen, H. Getty, J.Z. Hamdallah, I.N. Ali, M.R. (2011). Epidemiology and economic impact of obesity and type 2 diabetes. Surg. Clin. N. Am., 91: 1163-1172.

Smits, J.A., Rosenfield, D., Mather, A.A., et al. (2010). Psychotropic medication use mediates the 
relationship between mood and anxiety disorders and obesity: findings from a nationally representative sample. J Psychiatr Res., 44:10101016.

Sund, E.R., Jones, A., Midthjell, K. (2010). Individual, family, and area predictors of BMI and BMI change in an adult Norwegian population: findings from the HUNT study. Soc Sci Med., 70:1194-1202.

Torres, S.J., Nowsonm C.A. (2007). Relationship between stress, eating behavior, and obesity. Nutrition, 23: 887-894.

Trogdon, J.G., Finkelstein, E.A., Feagan, C.W., Cohen, J.W. (2012). State- and payer-specific estimates of annual medical expenditures attributable to obesity. Obesity, 20: 214-220.

Villareal, D.T., Apovian, C.M., Kushner, R.F., and Klein, S. (2005). Obesity in older adults: technical review and position statement of the American Society for Nutrition and NAASO, The Obesity Society. Am J Clin Nutr., 2:923-934.

Wang, Y., Beydoun, M.A. (2007). The obesity epidemic in the United States-gender, age, socioeconomic, racial/ethnic, and geographic characteristics: a systematic review and metaregression analysis. Epidemiol Rev., 29:6-28. doi:10.1093/epirev/mxm007.

World Health Organization. Definition, Diagnosis and Classification of Diabetes Mellitus and Its Complications. Part 1: Diagnosis and Classification of Diabetes Mellitus. 1999. http://whqlibdoc.who.int/hq/1999/who_ncd_ncs_99. 2.pdf. Accessed 21 Feb 2014.

Zellner, D.A., Loaiza, S., Gonzalez, Z., Pita, J., Morales, J., Pecora, D., et al. (2006). Food selection changes under stress. Physiol Behav., 87:789-793. 